\title{
DIGITAL LOYALTY FOR SOCIAL MEDIA, A CASE STUDY ON BOXPLOSIVE B.V.
}

\author{
Christopher Pandoyo ${ }^{1}$, Djoni Haryadi Setiabudi ${ }^{2 *}$ \\ ${ }^{1}$ Information Communication Technology \& Business Fontys University of Applied Sciences Eindhoven, Netherlands \\ Email: christopherpandoyo@gmail.com \\ ${ }^{2}$ Informatics Department, Petra Christian University, Surabaya, Indonesia \\ Email:djonihs@petra.ac.id \\ *Korespondensi penulis
}

\begin{abstract}
Digital loyalty is the process of providing incentives to customers through digital media to increase customer loyalty. Nowadays, Boxplosive B.V. using app to distribute deal and saver cards from retailers like $\mathrm{AH}$ to go and Etos to their customer. But the problem is that not all the customers are willing to download the app. To overcome this problem, this research investigate how social media app can be used for distributing deal and saver card. Therefore, a prototype program will be built for the implementation to show that social media app can be used for business purposes. The result shows that now the customer do not need to download the separate apps to get the deas and saver card.
\end{abstract}

Keywords: Digital loyalty; Social media.

\section{INTRODUCTION}

Emails have been a way of communication back in the 90's where email was firstly invented during that era. But as the time flow, new generations (current generation) are more into social media apps. Social media apps can be apps like Facebook Messenger, WeChat, Telegram, Viber or Line. Mostly they use these social media apps for their day to day communication.

Boxplosive B.V. was founded in 2009 at Tilburg, The Netherland and they had success with the business idea of digital loyalty. [1] They had successfully attracted retailers like $\mathrm{AH}$ to go and Etos by having their eyes for digital loyalty

Within social media app, people can deliver their personal message chat with real-time text transmission over the internet. Since smartphone exist and continually grow nowadays, low cost or free chat and social messaging apps are starting to appear and trying to be an alternative to operator-based text messaging via SMS. Many social media apps might feature group charts, sending images and videos, Voice over IP or even stickers and emoticons.

Boxplosive B.V. has an existing platform to provide deals and digital stamps of $\mathrm{AH}$ to go and Etos. For now, the deals and digital stamps are available from within the $\mathrm{AH}$ to go and Etos apps itself.

Retailers like $\mathrm{AH}$ to go and Etos want to reach more potential customers. The Boxplosive Loyalty Platform is already integrated into their apps. Building and distributing a digital loyalty app brings problems. Those problems are: it costs a lot of effort, not all people are willing to download a new digital loyalty app and it is a new area for Boxplosive to distribute deals and digital stamps.

It be great if customer can receive deals and digital stamps within a Social Media App that is already present on their phone. As the time went by Boxplosive B.V. want to further explore whole new area business which will be trending in the near future. Therefore this research intended to explore digital loyalty within the social media.

\section{DIGITAL LOYALTY}

Customer loyalty is the tendency of a customer to like a brand over another brand, can be caused by satisfaction of a product or service, comfort or performance or just familiarize with the brand. Customer loyalty will trigger customers to spend more consistently, spend more money on the product and feel positive about shopping experience.

With the rise in popularity of mobile devices, stores are now choose to implement a digital, smartphone-based system. The advantages of using digital loyalty are: first, the vendors can track customer purchases and redemptions, providing the ability to target offers based on customer behavior. This promotes a more personalized consumer experience and strengthens the merchant-consumer relationship and loyalty. Second, it is easy to use, that the customer can earn and redeem reward points without digging in your pockets for cards. Consumers and businesses both benefit because the system is automated. Third, it is efficient, digitally-powered reward systems are empowered with data that helps drive smarter decisions and allows businesses to send out specials to smartphones that are likely to be read. The example of 
using loyalty program is Fivestars, this company using mobile app that give points for purchases which customers can redeem for prizes. The company also runs email, SMS, and push notification promotions on behalf of participating businesses. The other is Belly. This company offer a multifaceted platform that helps increase customer frequency and retention, collects customer data, manages email and social media channels, monitors online reputation, and drives customer acquisition through product and service sampling. [2]

\section{RESEARCH PHASING}

The first phase to start the research is to plan for the whole upcoming work. Planning is required to keep this research right on track and according to the schedule, planning includes preparing the research plan and gather informational requirement. Second phase is research part. Research part was done using Library, Field, Workshop, Lab strategies that was introduced from DOTS framework. Besides doing research looking tutorial examples in the internet will be necessary to follow up the material. After gathering examples and knowing the process then time to process to the build phase. Proof of concept will be build and developed during the build phase. The last phase is to test the proof of concept within some internal users that work at Boxplosive.

\section{CHOOSING WHICH SOCIAL MEDIA APP PLATFORM}

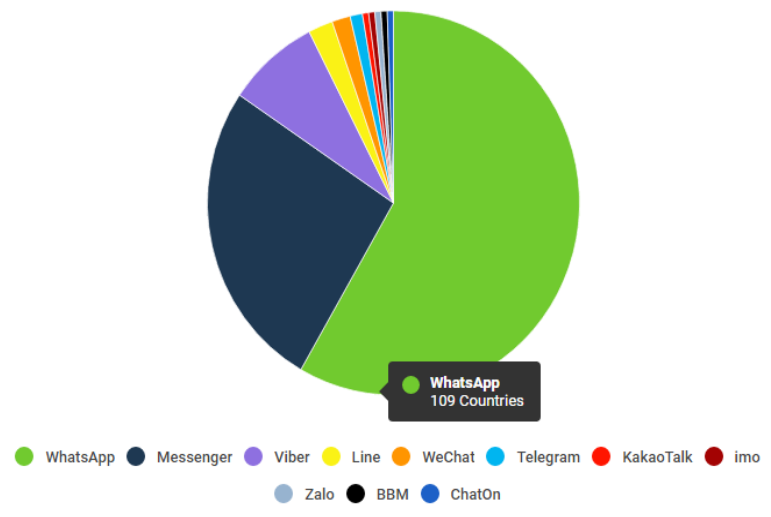

Figure 1. Social Media popularity pie chart

From Fig. 1, it was known that there are some social media app that is popular to each country. It is known WhatsApp was the leader of all around the world claiming around 109 countries, it is almost $55.6 \%$ of the world. Followed by Facebook Messenger in second place, claiming almost 49 countries [3]. Viber is also following behind in the third place and it appears that Viber is having popularity in Eastern Europe like Belarus, Moldova, Ukraine, and others. Telegram is quite popular in Russia as well. WeChat might be huge following as well but it is only used by the Chinese because every other messenger app was blocked in China, which is why whole China nation needs to use WeChat. Another famous chat app that is famous in Asia is Line. Line is being used in Japan, Thailand and Taiwan.

\section{WhatsApp}

\section{Does WhatsApp support automation reply?}

The first step to find examples on the internet. After searching for 1 hour on the internet, no examples were found. According to a topic discussion on Quora website, people were also giving answers that there is no such way to build an automated reply in WhatsApp [4].

\section{Why there were no examples of WhatsApp?}

WhatsApp does not want their application to be interrupted at any chance. WhatsApp Policy had written on their website and have stated their terms and policies at https://www.whatsapp.com/legal/\# terms-of-service with the sub-title "using acceptable use of WhatsApp services". WhatsApp is afraid that by supporting automation reply will harm WhatsApp itself and their users. According to WhatsApp Inc (2017) website "Harm to WhatsApp or Our Users. You must not (or assist others to) access, use, copy, adapt, modify, prepare derivative works based upon, distribute, license, sublicense, transfer, display, perform, or otherwise exploit our Services in impermissible or unauthorized manners, or in ways that burden, impair, or harm us, our Services, systems, our users, or others, including that you must not directly or through automated means: (a) reverse engineer, alter, modify, create derivative works from, decompile, or extract code from our Services; (b) send, store, or transmit viruses or other harmful computer code through or onto our Services; (c) gain or attempt to gain unauthorized access to our Services or systems; $(d)$ interfere with or disrupt the integrity or performance of our Services; (e) create accounts for our Services through unauthorized or automated means; ( $f$ ) collect the information of or about our users in any impermissible or unauthorized manner; (g) sell, resell, rent, or charge for our Services; or ( $h$ ) distribute or make our Services available over a network where they could be used by multiple devices at the same time."

This means if WhatsApp found a violation with the term of usage and policies, then WhatsApp have the right to ban the account of user which has violated the rules from using WhatsApp [5]. In other words, the big answer is no! 


\section{Facebook}

\section{Is there any example using Facebook Messenger?}

The first step is to find example, and the example that had been found was $\mathrm{CNN}$. The reason that $\mathrm{CNN}$ is being picked due to its reputation. $\mathrm{CNN}$ already popular among the news company. According to $\mathrm{CNN}, \mathrm{CNN}$ is the world's leader in online news and information delivery. CNN has relied on 4,000 Global teams of news professional spread worldwide. They always feature the latest multimedia, technologies, or even using live video streaming. Now they had implemented another breakthrough by sending news through social media apps. Starting now people can receive news within the Facebook Messenger [6].

Fig. 2 shows that user can initiate a conversation with the CNN account and then will be followed by a question on which topic does the user prefer. CNN also provide some card news for user to choose. After selecting the preferred news topic that has been chosen by the user, user can either read, ask and even get a summary.

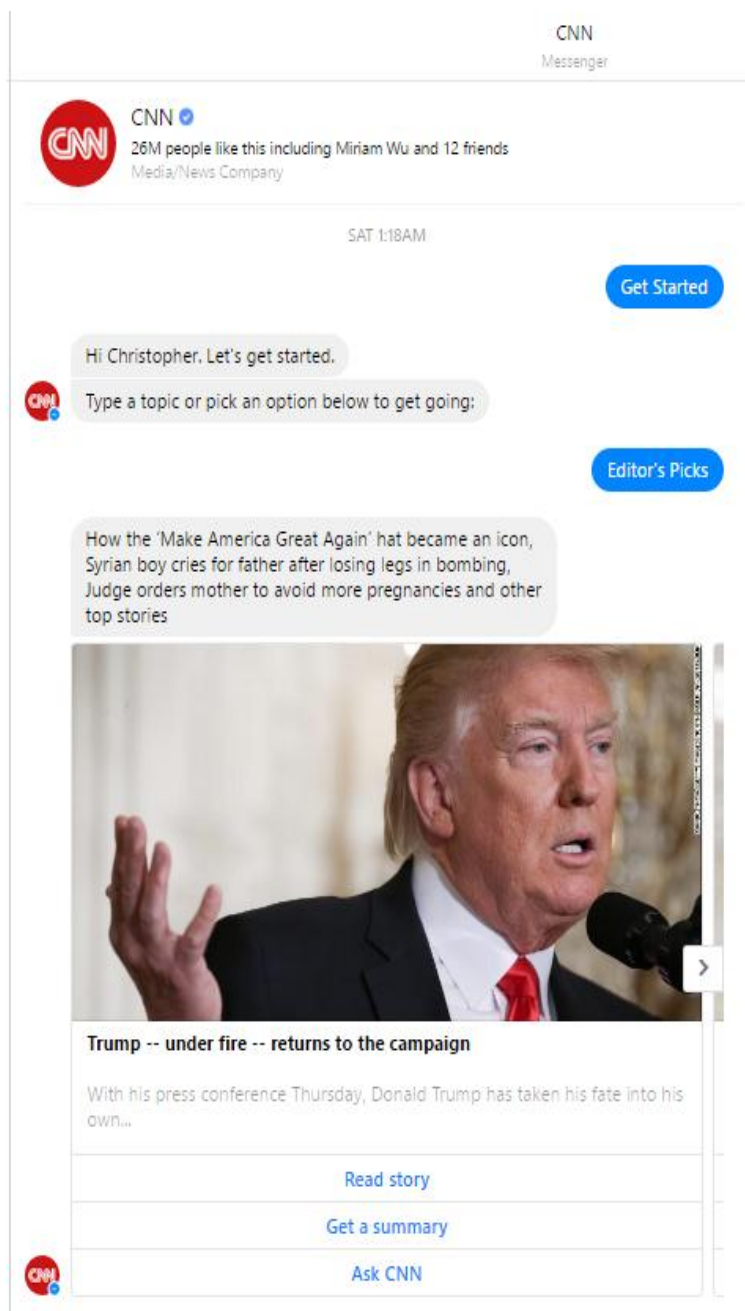

Figure 2. CNN example
3 options above will do the following:

a. Read the story will redirect the users to CNN.com website so users can read the detail news directly on the website

b. Get a summary, then a summarize of the story will be sent to a user using chat text

c. Ask CNN by telling CNN 1 or 2 words and CNN will try to find relevant information

\section{Does Facebook support automation reply?}

Facebook explained to developer, that Facebook allows developer to build an automation reply within the Facebook Messenger using the Facebook Messenger platform which supports an automated reply to users. Facebook mentioned that using Facebook Messenger will help business to reach their customer who's already been using Facebook Messenger [7]. In other words, yes Facebook Messenger supports automation reply.

\section{HOW TO CONNECT WITH BOXPLOSIVE LOYALTY PLATFORM}

According to Swanner, Facebook has officially launched its chatbot API for Facebook Messenger on 2016 and it is called "Messenger Platform". This API can help developers to build an automated reply inside Facebook Messenger. The chatbot also offer richer menus which allow to send links, show images and provide information [7].

According to Facebook, there are procedures to launch the automated reply program inside Facebook Messenger [8]:

1. Test your bot: Developer needs to build the automated reply with code and then test wether the code works or not

2. Submit app to be reviewed: When developer has finished developing the automated reply, developer can submit the app along with it source code to Facebook

3. Make your app public: After Facebook fully complete finished reviewing the developer's app, then Facebook will allow the app to be launch in public and everyone will be able to use it.

There are some notes from Facebook to developers:

a. "When your app is in Development Mode, your bot will work for admins, developers and testers of the app. After your app is approved and public, it will work for the general public."

b. Once you are ready to launch your bot, please submit your app for review.

c. Your bot will then be tested by our team to ensure it's compliant with our Platform Policies. 
As developing directly using "Messenger Platform" API takes more time to test due to some test requirement by Facebook. Then the alternative solution is to look for another 3rd party tool which can be integrated with Facebook Messenger directly without the need to wait for the submit and reviewing process.

According to a question in Quora website, there are answers about several 3rd party platforms which are possible to be connected with Facebook Messenger platform. Those 3rd party platforms are Motion. ai and Chatfuel [9].

Comparison between those 2 tools are simplified on table 1 down below.

Table 1. Tools Comparison Table

\begin{tabular}{lll}
\hline Features & Chatfuel & Motion.ai \\
\hline Dashboard & $\begin{array}{l}\text { Yes, simple } \\
\text { does not have } \\
\text { any visual } \\
\text { flowchart }\end{array}$ & $\begin{array}{l}\text { Yes, full of visual } \\
\text { like flowchart }\end{array}$ \\
\hline $\begin{array}{l}\text { Customizing } \\
\text { within each } \\
\text { state }\end{array}$ & $\begin{array}{l}\text { Yes, more } \\
\text { friendly user } \\
\text { interface which } \\
\text { allow user to } \\
\text { put in contents } \\
\text { more easily }\end{array}$ & $\begin{array}{l}\text { Yes, more } \\
\text { complicated } \\
\text { because lots of } \\
\text { textbox design }\end{array}$ \\
\hline $\begin{array}{l}\text { Support } \\
\text { coding }\end{array}$ & $\begin{array}{l}\text { Yes, using } \\
\text { JSON API then } \\
\text { call the website } \\
\text { and run the } \\
\text { script }\end{array}$ & Yes, using node.js \\
\hline Free & $\begin{array}{l}\text { Yes, it is free up } \\
\text { to 500.000 users } \\
\text { per month }\end{array}$ & $\begin{array}{l}\text { Yes, up to } 1000 \\
\text { messages received } \\
\text { per month }\end{array}$ \\
\hline
\end{tabular}

\section{PROOF OF CONCEPT}

\section{Registration}

The first step before activating deal, user is required to register to the messenger first then activate the account from email that they have received and last step user is required to login with their registered credentials.

The scenario for the user to register is:

- On the main menu user has to click on start now $\rightarrow$ register $\rightarrow$ register new as seen as in Fig. 3 down below.

- Then the messenger will ask for new email address and password to be registered.

- After filling in the email address and password, then user will receive an email as seen as in Fig. 4 down below.

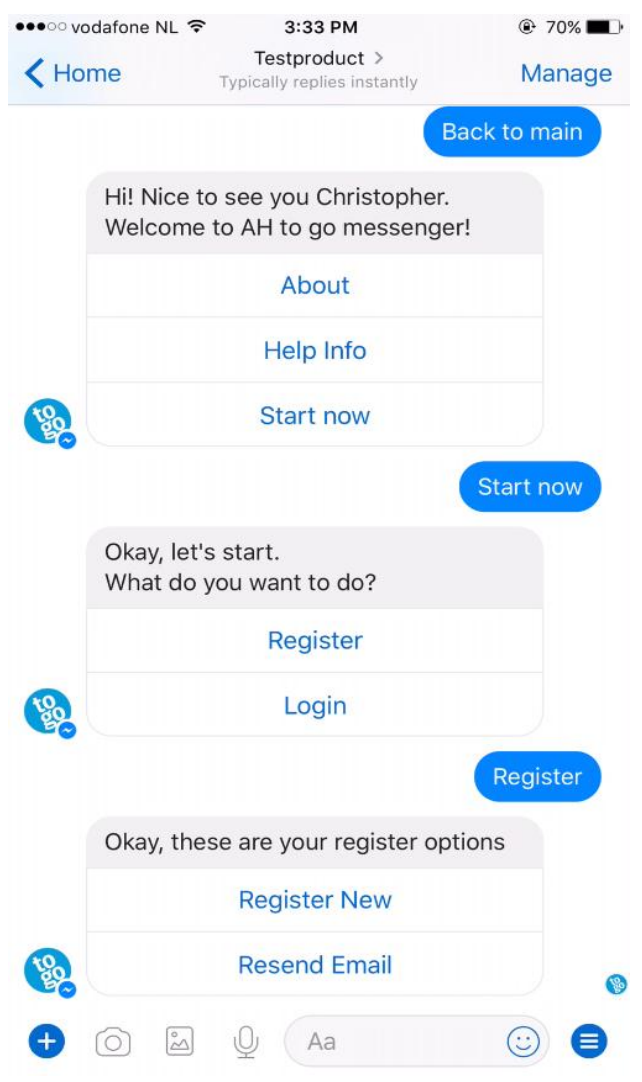

Figure 3. Register part 1

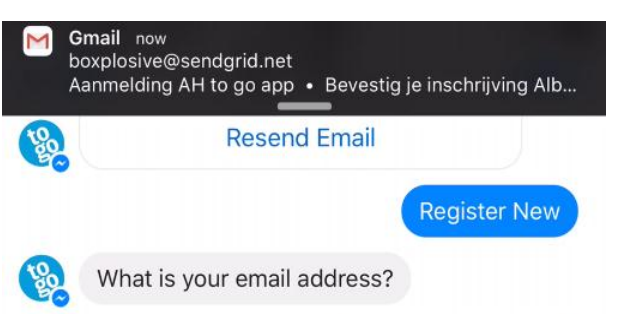

christopher.pandoyo +15@boxplosive.nl

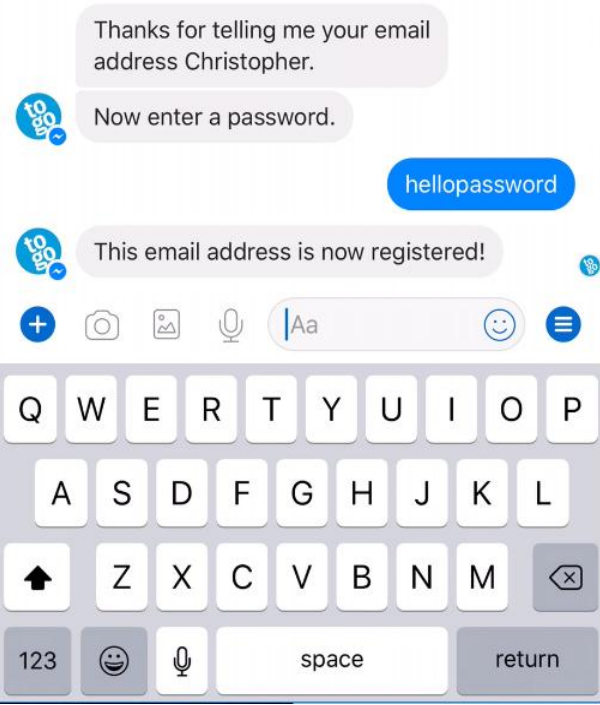

Figure 4. Register part 2 


\section{Login}

The scenario for the user to login is:

- On the main menu user has to click on start now $\rightarrow$ login as seen as in Fig. 5 down below.

- Then the messenger will ask for registered email address and password.

- After filling in the email address and password, then user will be successfully logged in as seen as in Fig. 6 down below.

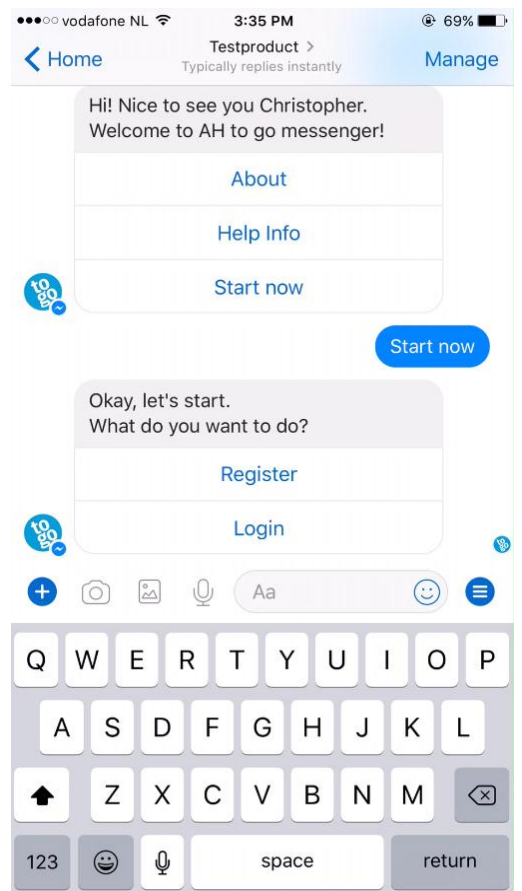

Figure 5. Login part 1

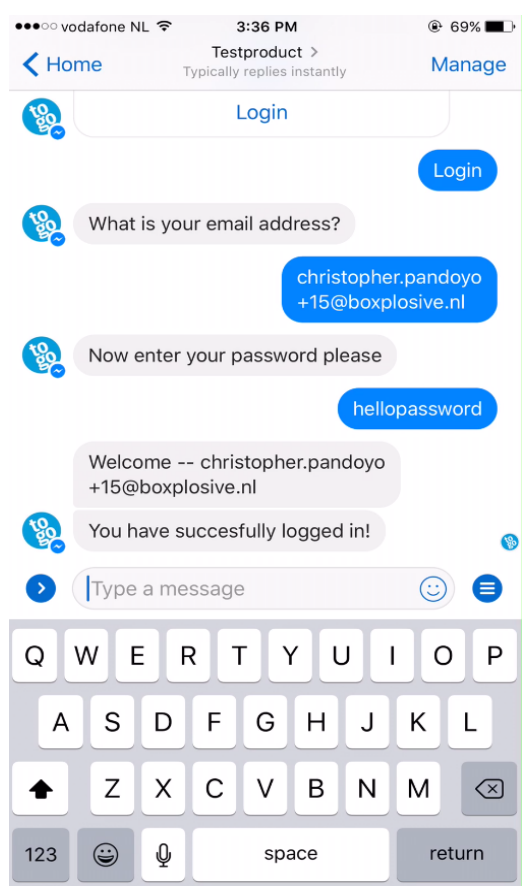

Figure 6. Login part 2

\section{Deals}

After successfully logged in then user is able to view and claim a deal.

The scenario to claim the deal is:

- Type "deals" anytime on the screen as seen in Fig. 7 down below.

- The messenger will give the available deals to user as seen in Fig. 8 down below.

- User need to claims one among the deals.

- The deal can be claimed later on.

- User can see activated deals by typing "active deals" anytime on the screen to check their claimed deals.

- User can click send me my card to retrieve the barcode to be scanned at supermarket cashier.

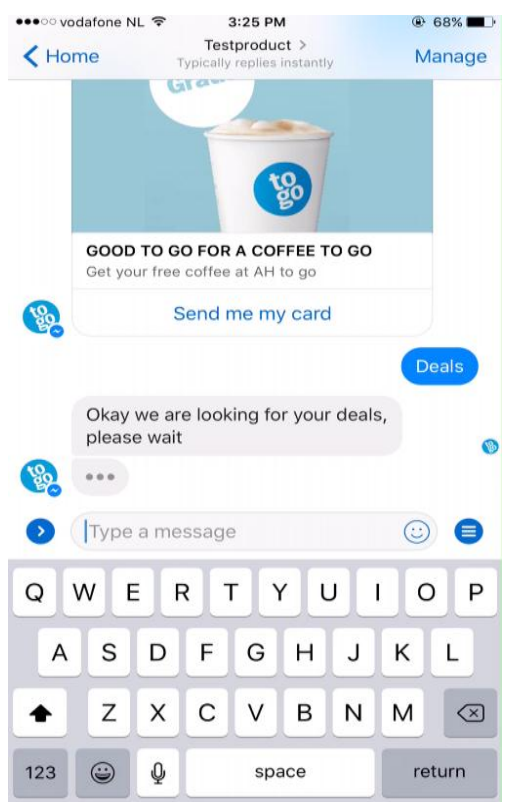

Figure 7. Asking for deals

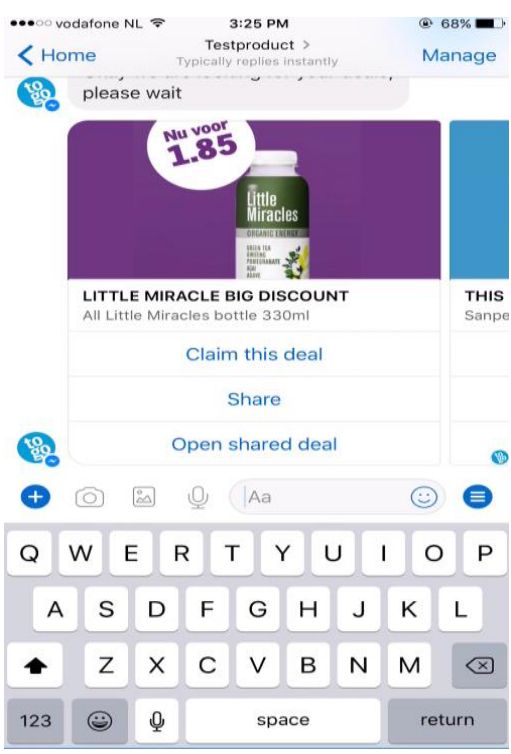

Figure 8. Receiving deals 


\section{CONCLUSION}

It is possible to make an automation reply within social media apps especially Facebook Messenger because it is supported and they provide an official support of the open API for developers and with the following help of 3rd party tool like Chatfuel which help to fasten the process by bypassing the app review process by Facebook, unlike WhatsApp which has not provided any support yet to developers even though WhatsApp is the world most leading social media app for communicating people. Distributing deals and saver card inside Facebook Messenger will raise awareness of customer about supermarket and provide simple access for customer. Customer will no longer need to download individual separate apps to get the deals and saver card.

\section{ACKNOWLEDGMENT}

This research can be conducted and accomplished by permission from Boxplosive. We would like to thanks also to Fontys University of Applied Science foe supporting this research.

\section{REFERENCES}

[1] Chaney, Paul.How to Use Digital Loyalty Programs to Retain Customers. http://www.practicalecommerce.com/how-to-use-digital-loyaltyprograms-to-retain-customers, Retrieved August 2,2017.

[2] Boxplosive. http://www.boxplosive.nl/en/paginas/ 1-loyalty-promotion.html
[3] Schawrtz, J. The Most Popular Messaging App in Every Country. Retrieved March 10, 2017, from https://www.similarweb.com/blog/worldwide-messaging-apps.

[4] Quora. Is there a way to set up an automated WhatsApp reply to any message you receive? Retrieved March 20, 2017, from https://www. quora.com/Is-there-a-way-to-set-up-an-automated-WhatsApp-reply-to-any-message-youreceive.

[5] WhatsApp Inc. WhatsApp Legal Info. Retrieved March 20, 2017, from https://www.whatsapp. com/legal/\#terms-of-service.

[6] CNN. About CNN.com. Retrieved March 20, 2017, from http://edition.cnn.com/2014/01/17 /cnn-info/about/index.html.

[7] Swanner, N. Facebook officially launches its Messenger Platform developer chatbot API. Retrieved May 2, 2017, from https://thenextweb. com/dd/2016/04/12/facebook-messengerchatbot-platform/\#.tnw_kOHHe0VK.

[8] Facebook for developers. Messenger Platform Getting Started - Launching your bot. Retrieved May 2, 2017, from https://developers.facebook. com/docs/messenger-platform/product-overview/ launch\#app_review.

[9] Quora. What are the best Chat Bot building platforms - code based or "click and drag" apps? Why?. Retrieved May 1, 2017, from https:// www.quora.com/What-are-the-best-Chat-Botbuilding-platforms-code-based-or-click-anddrag-apps-Why\#. 